\title{
Increased influenza vaccination rates in patients with autoimmune rheumatic diseases during the Covid-19 pandemic: a cross-sectional study
}

\author{
George E. Fragoulis ${ }^{1}\left[\right.$ - loannis Grigoropoulos ${ }^{2} \cdot$ Evgenia Mavrea $^{2} \cdot$ Aikaterini Arida $^{1}$ (D) \\ Vassiliki-Kalliopi Bournia ${ }^{1}$ (1) Gerasimos Evangelatos ${ }^{1}\left[\right.$ Galliopi Fragiadaki $^{1} \cdot$ Anastasios Karamanakos $^{1}$.

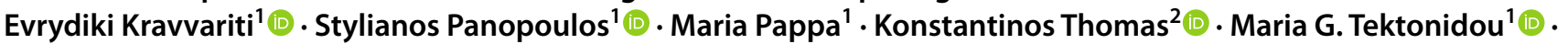 \\ Dimitrios Paraskevis $^{3} \mathbb{D}$. Dimitrios Vassilopoulos ${ }^{2} \mathbb{D} \cdot$ Petros P. Sfikakis $^{1} \mathbb{D}$
}

Received: 27 January 2021 / Accepted: 16 February 2021 / Published online: 4 March 2021

(c) The Author(s), under exclusive licence to Springer-Verlag GmbH, DE part of Springer Nature 2021

\begin{abstract}
To assess non-compliance and potential changes in seasonal flu vaccination coverage before and during the Covid-19 pandemic in patients with autoimmune rheumatic diseases (ARDs). Consecutive patients with ARDs followed-up in 2 tertiary hospitals were telephone-interviewed (December 12-30,2020) regarding seasonal flu vaccination during the 2019/20 and 2020/21 time periods. Self-reported disease flares that occurred after flu vaccination, as well as reasons for non-vaccination were recorded.One thousand fifteen patients were included. The rate of flu vaccination increased from $76 \%$ before to $83 \%$ during the COVID-19 pandemic $(p=0.0001)$. The rate of self-reported disease flares was $<1 \%$ among vaccinated patients. Reasons for not vaccination in both periods, respectively, included: 'was not recommended by their rheumatologists' (35.0vs.12.2\%, $p<0.0001)$, 'did not feel that they would have any benefit' (36.9 vs. $32.6 \%$ ), felt unsafe to do so ( 27.5 vs. $30.2 \%$ ), or other reasons (18.9 vs. $23.8 \%$ ). By multivariate analysis, age [OR $=1.03$ (95\% CI 1.02-1.04)] vs. [1.04 (95\% CI 1.02-1.05)] and treatment with biologics [OR $=1.66$ (95\% CI 1.22-2.24) vs. [1.68 (95\% CI 1.19-2.38)] were independent factors associated with vaccination in both periods. These findings, although are temporally encouraging, emphasize the need for continuous campaigns aiming at increasing patients' and physicians' awareness about the benefits of vaccination.
\end{abstract}

Keywords Vaccination $\cdot$ Influenza $\cdot$ Autoimmune rheumatic diseases $\cdot$ Covid-19

\section{Introduction}

The higher risk for infections in patients with autoimmune rheumatic diseases (ARDs) is well established [1,2]. In this context, vaccinations are of paramount importance in this population. As outlined in EULAR recommendations, flu vaccination should be strongly considered for the majority of patients with ARDs [3] since it has been shown that is associated with reduced mortality, hospitalizations risk and influenza-related complications [3,4].

Vaccination rates in ARD patients vary and few studies have assessed the factors that are associated with noncompliance. Covid-19 pandemic, added another factor of

George E. Fragoulis

geofragoul@yahoo.gr

Extended author information available on the last page of the article complexity as it has generated some degree of uncertainty in these patients [5]. Covid-19 virus entered our lives, suddenly, in December 2019, when a cluster of patients with lower respiratory tract infection was described in the province of Wuhan, in China [6]. Covid-19 is the seventh member of the corona-viruses that can infect humans [6] and its name is derived from the spikes that are present on its surface (Fig. 1). Although its origin is not clear, a close homology to two bat-derived coronaviruses has been identified [7, 8]. Clinically, is mainly expressed with fever, headache, anosmia, fatigue and cough and not infrequently, leads to admission in the intensive care unit [9-12].

Aim of our study was to assess potential changes in influenza vaccination during the Covid-19 pandemic among ARD patients and investigate the factors associated with non-compliance. 


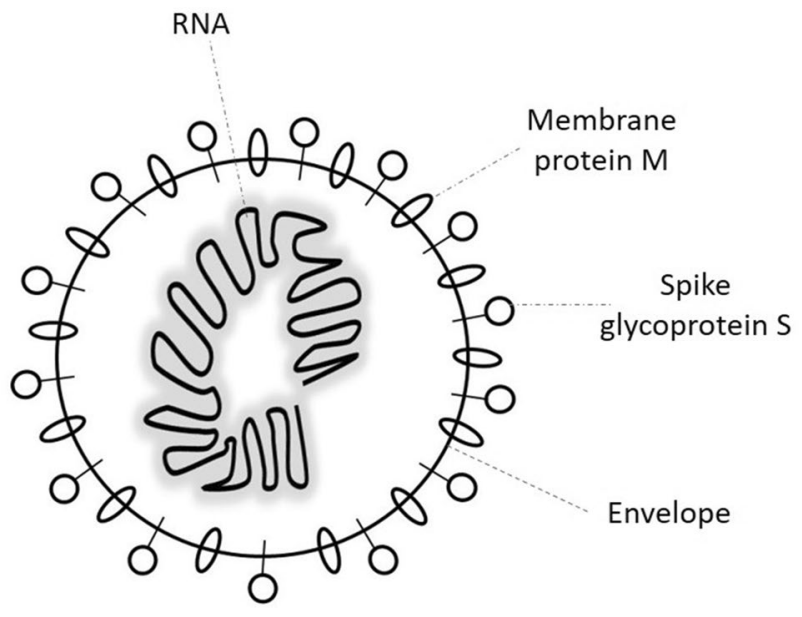

Fig. 1 Schematic depiction of the novel coronavirus

\section{Patients and methods}

In our cross-sectional, observational study, patients with ARDs who had been examined at least once during the last year in the outpatient rheumatology clinics of two tertiary hospitals were telephone-interviewed from 12/12/2020 to 30/12/2020.

Patients were consecutively enrolled, following an alphabetical order of their surname in our files. Patients with a diagnosis of osteoarthritis, crystal arthropathies and metabolic bone diseases were excluded. The following parameters were recorded: age, sex, level of education (1st level: elementary school, 2nd level: high school, 3rd level: college/university), employment status, smoking status, follow-up time (from disease diagnosis to enrollment in the study) and type of ARD (inflammatory arthritides: rheumatoid arthritis, spondyloarthropathies; connective tissue diseases: systemic lupus erythematosus, systemic sclerosis, dermatomyositis, Sjogren's syndrome, antiphospholipid syndrome, myositis; autoinflammatory diseases: adult-onset Still's disease, familial mediterannean fever; vasculitides: ANCA-associated vasculitis, Behcet's disease, giant cell arteritis), current treatment for ARDs (glucocorticoids, non-biologic immunosuppressives, targeted synthetic agents and biologics) and the presence of certain co-morbidities (hypertension, coronary heart disease, diabetes mellitus, chronic kidney disease, chronic obstructive pulmonary disease [COPD], history of malignancies and/or chemotherapy during the last 6 months).

A specific questionnaire, constructed by the investigators of this study specifically for this purpose, was used and included the following: Firstly, patients were asked if they had the inflenza vaccine in the periods 2019/20 and 2020/21 and if so, whether they had a disease flare that could be linked to vaccination. If they haven't been vaccinated, they were asked why that occured; the following options were given: (a) believe that flu-vaccination is not helpful, (b) do not feel safe to have the vaccination, (c) was not suggested by their doctor (d) was not their priority, due to the covid pandemic (for 2020/21), (e) other reasons (including forgot to take the vaccine, previously allergic on vaccination etc.).

Comparisons were made between patients who were vaccinated and those who did not, in the two different time periods (2019/20 and 2020/21). Also, patients who did not take the vaccine in 2019/20, but decided to get vaccinated in 2020/21, were compared with those who did not change their vaccination behaviour.

The current study was conducted according to the Declaration of Helsinki and was approved by the Scientific Council of the hospital (No: 2020/14/4).

\section{Statistics}

Fisher's exact and Mann-Whitney tests were used for categorical and continuous characteristics, respectively. Normality of data distribution was evaluated with Kolmogorov-Smirnov test. For parameters not normally distributed, results were expressed as median (range). Logistic regression analysis were performed using "vaccinated in the period 2019/20", "vaccinated in the period 2020/21", "vaccinated in both periods" as dependent variables, in three different models. Age, sex and parameters that demonstrated statistical significance in the univariate analyses served as independent variables. Statistical package SPSS 21.0 was used.

\section{Results}

\section{Patient characteristics}

In total, 1046 patients were called. From those, 1015 (97\%) patients responded. They were $75 \%$ females, with a median (range) age of 58 (18-82) years and a mean disease duration of 7 (0.5-50) years (Table 1$)$. The majority had inflammatory arthritides $(59.6 \%)$ or connective tissue diseases $(29.9 \%)$. Half of them were current or previous smokers. Their treatments and comorbidities are also shown in Table 1.

\section{Vaccination rates, reported disease flares and reasons for non-vaccination}

In the 2019-20 period, $76.0 \%(771 / 1015)$ of ARD patients were vaccinated against the flu while the respective figure climbed to $83.1 \%(843 / 1015)$ during the COVID-19 pandemic period $(2020 / 21, p=0.0001)$. The respective rates 
Patient characteristics

$N$

Age (years), median (range)

1015

Females, $n(\%)$

Disease duration, years, median (range)

Type of ARD, $n(\%)$

Inflammatory arthritis

Connective tissue diseases

Auto-inflammatory diseases

Primary systemic vasculitides

Educational status, $n(\%)$

$1^{\text {st }}$ level

$2^{\text {nd }}$ level

$3^{\text {rd level }}$

Employment status, $n(\%)$

Unemployed

Employed

Retired

Smoking, $n(\%)$

Never

Previous

Current

Therapy

Glucocorticoids, $n(\%)$

Non-biologics, $n(\%)$

Biologics, $n(\%)$

Co-morbidities

Hypertension, $n(\%)$

Coronary artery disease

Heart failure, $n(\%)$

Diabetes mellitus, $n(\%)$

Chronic Kidney Disease, $n(\%)$

Chronic Obstructive Pulmonary Disease, $n(\%)$

Neoplasia history, $n(\%)$

Chemotherapy, $n(\%)$

$n$ number, $S D$ standard deviation
Table 1 Patient characteristics
$58(18-82)$

$758(74.7 \%)$

$7(0.5-50)$

$605(59.6 \%)$

$304(29.9 \%)$

$20(2.0 \%)$

$86(8.5 \%)$

$210(20.7 \%)$

$444(43.7 \%)$

$361(35.6 \%)$

$176(17.4 \%)$

$468(46.1 \%)$

$371(36.5 \%)$

$499(49.2 \%)$

$268(26.4 \%)$

$248(24.4 \%)$

$371(36.6 \%)$

$667(65.7 \%)$

$575(56.7 \%)$

$358(35.3 \%)$

$64(6.3 \%)$

$18(1.8 \%)$

$99(9.7 \%)$

$67(6.6 \%)$

$44(4.3 \%)$

$74(7.3 \%)$

$4(0.4 \%)$

\section{Comparison of patients' characteristics between those who did and those who did not vaccinate}

During the two consecutive time periods (2019/20 and 2020/21), older patients, those on biologics and those with certain comorbidities such as hypertension and diabetes mellitus were most likely to get vaccinated (Table 2). Similarly, comparing patients who were vaccinated in both time periods $(2019 / 2021)(n=774)$ with those who were never vaccinated $(n=145)$, it was recorded that the former were older, more commonly on biologics or had comorbidities like hypertension, diabetes and COPD (Table 3).

By multivariate analysis, it was found that vaccination was associated for both periods, assessed individually or combined, with age [2019/20: OR $=1.03(95 \%$ CI 1.02-1.04), 2020/21: OR $=1.04$ (95\% CI 1.02-1.05), 2019/21: OR $=1.04(1.02-1.05)]$ and treatment with biologics [2019-20: OR $=1.66$ (95\% CI 1.22-2.24), 2020/21: $\mathrm{OR}=1.68$. (95\% CI 1.19-2.38), 2019/21: OR $=1.90$ (1.30-2.77)].

\section{Change in vaccination behaviour}

Twenty-seven (2.7\%) patients had the vaccine in 2019/20 but not during the COVID-19 period (2020/21). Only 7.4\% did that because they thought that flu-vaccine was not their priority due to the COVID-19 pandemic. The most common reason was they forgot/had other reasons $(63.0 \%)$ while the rest did not do it for safety concerns (18.5\%), did not think that flu-vaccine was helpful (7.4\%) and not recommended by their rheumatologist (3.7\%).

On the other hand, 99 patients $(9.8 \%)$ had their vaccine during the COVID-19 period but not in the previous year. These newly vaccinated patients compared to the patients that they did not change their vaccination behaviour $(n=889)$, were younger, had a shorter disease duration, were more frequently of higher education level and had less commonly hypertension (Table 4).

\section{Discussion}

of self-reported disease flares after vaccination were $<1 \%$ (2019/20: 0.3\%, 2/771, 2020/21: 0.7\%, 6/843).

The main reasons for non-vaccination in these 2 time periods were the belief that this would not be helpful (2019-20:36.9\%, 2020-21:32.6\%, $p=0.41)$, the fear of side effects $(2019 / 20: 27.5 \%, 2020 / 21: 30.2 \%, p=0.58)$, the absence of a recommendation from the treating physician $(2019 / 20: 35 \%, 2020 / 21: 12 \%, p=0.0001)$ and other reasons including forgetfulness about the vaccination (2019/20:18.9\%, 2020/21:23.8\%, $p=0.22$ ).
Vaccination against flu is strongly recommended in patients with ARD [3]. The effect that COVID-19 could have had in flu-vaccination uptake has not been studied so far. This is the first study showing that in a real-world population with ARDs, coverage for flu vaccination has increased during the Covid-19 pandemic era. In fact, there was a statistically significant increase from 76 to $83.1 \%$. In a recent survey of the Italian general population, the rate of those who were willing to get the flu vaccine the $2020 / 21$ period was $44 \%$, compared to $27 \%$ of individuals who had the vaccine in 2019/20 [13]. 
Table 2 Comparison of patients' characteristics between those who were vaccinated and those who did not, during the 2 vaccination periods (2019-20 and 2020-21)

\begin{tabular}{|c|c|c|c|c|c|c|}
\hline & \multicolumn{3}{|c|}{ Vaccination period 2019-20 } & \multicolumn{3}{|c|}{ Vaccination period 2020-21 } \\
\hline & Yes $(n=771)$ & No $(n=244)$ & $p$ & Yes $(n=843)$ & No $(n=172)$ & $p$ \\
\hline Age (years), median (range) & $60(18-82)$ & $50(19-80)$ & 0.0001 & $59(18-82)$ & $48(21-80)$ & 0.0001 \\
\hline Female gender, $n(\%)$ & $571(74.1)$ & $187(87.4)$ & 0.448 & 629 & 129 & 1.000 \\
\hline Disease duration (years), median (range) & $7(0.5-50)$ & $6(0.5-48)$ & 0.02 & $7(0.5-50)$ & $7(0.5-48)$ & 0.686 \\
\hline $\begin{array}{l}\text { Type of ARD } \\
\text { Inflammatory arthritis } \\
\text { Connective tissue diseases } \\
\text { Auto-inflammatory diseases } \\
\text { Vasculitis }\end{array}$ & $\begin{array}{l}465 \\
225 \\
16 \\
65\end{array}$ & $\begin{array}{l}140 \\
79 \\
4 \\
21\end{array}$ & 0.781 & $\begin{array}{l}510 \\
242 \\
16 \\
75\end{array}$ & $\begin{array}{l}95 \\
62 \\
4 \\
11\end{array}$ & 0.219 \\
\hline Higher Educational status, $n(\%)$ & $253(32.8)$ & $108(44.3)$ & 0.001 & $292(34.6)$ & $69(40.1)$ & 0.190 \\
\hline Unemployed, $n(\%)$ & $131(17.0)$ & $45(18.4)$ & 0.628 & $147(17.4)$ & $29(16.9)$ & 0.912 \\
\hline Current smokers, $n(\%)$ & $186(24.1)$ & $62(25.4)$ & 0.670 & $205(24.3)$ & $43(25.0)$ & 0.846 \\
\hline \multicolumn{7}{|l|}{ Therapy } \\
\hline Glucocorticoids, $n(\%)$ & $287(37.2)$ & $84(34.4)$ & 0.127 & 317 (37.6) & $52(30.2)$ & 0.018 \\
\hline Non-biologics, $n(\%)$ & $514(66.7)$ & $153(62.7)$ & 0.426 & $553(65.6)$ & $110(64.0)$ & 0.736 \\
\hline Biologics, $n(\%)$ & $450(58.4)$ & $115(47.1)$ & 0.003 & $486(57.7)$ & $79(45.9)$ & 0.009 \\
\hline \multicolumn{7}{|l|}{ Co-morbidities } \\
\hline Hypertension, $n(\%)$ & 305 (39.6) & $53(21.7)$ & 0.0001 & $318(37.7)$ & $40(23.2)$ & 0.0001 \\
\hline Coronary artery disease, $n(\%)$ & $55(7.1)$ & $9(3.7)$ & 0.068 & $57(6.8)$ & $7(4.1)$ & 0.229 \\
\hline Heart failure, $n(\%)$ & $15(1.9)$ & $3(1.2)$ & 0.586 & $15(1.8)$ & $3(1.7)$ & 1.000 \\
\hline Diabetes mellitus, $n(\%)$ & $85(11.0)$ & $14(5.7)$ & 0.013 & $91(10.8)$ & $8(4.7)$ & 0.011 \\
\hline Chronic Kidney Disease, $n(\%)$ & $58(7.5)$ & $9(3.7)$ & 0.038 & $60(7.1)$ & $7(4.1)$ & 0.177 \\
\hline Chronic Obstructive Pulmonary Disease, $n(\%)$ & $40(5.2)$ & $4(1.6)$ & 0.018 & $41(4.9)$ & $3(1.7)$ & 0.097 \\
\hline Neoplasia history, $n(\%)$ & $59(7.7)$ & $15(6.1)$ & 0.482 & $60(7.1)$ & $14(8.1)$ & 0.630 \\
\hline Chemotherapy, $n(\%)$ & $4(0.5)$ & $0(0.0)$ & 0.578 & $3(0.4)$ & $1(0.6)$ & 0.525 \\
\hline
\end{tabular}

Significant values $(p<0.05)$ are marked with bold.

$n$ number, $S D$ standard deviation

The uptake of influenza vaccination varies across different countries and time periods, reflecting diversities in the studies' design, health-system and culture differences, as well as the increasing awareness about vaccinations [14-17]. The majority of the studies, pertain RA, in which vaccination rates ranges from 25 to $90 \%$ [18]. In a registry-based study with RA patients a few years ago in Greece showed that the coverage for influenza vaccine was only 54\% [19]. Also, recent studies investigating the vaccination rate in patients with other non-rheumatic chronic disorders showed that $40-55 \%$ were vaccinated $[20,21]$. It seems, therefore, that campaigns ran by rheumatology societies about vaccinations have a significant effect in the care of ARD patients over the last years.

In concert with other studies [14-16], we found that vaccination uptake was higher by patients who have other comorbidities and by older people. Reassuringly, we found that younger people changed their behaviour for flu vaccination during the last year.

In addition, we found that only a small percentage of the patients $(0.26-0.7 \%)$ experienced a flare of their disease after vaccination. This is consistent with most studies which have shown that although transient autoantibody development can be observed, flu vaccination did not alter disease activity in ARD patients [3, 22-25].

Regarding the reasons for non-vaccination in our study, the fear of adverse effects and the notion that the flu vaccine is not helpful were equally important. Noteworthy, one third of the patients, before the Covid-19 pandemic, were not vaccinated because this was not suggested by their doctor. This, however, has dramatically changed the last year. Lack of awareness and fear for flu vaccinations have been identified by other studies, focused in inflammatory arthritis, as major causes of non-vaccination in similar percentages (i.e. $20-30 \%$, each) $[16,26]$.

Our study has certain advantages and limitations. It is a large, real-world study covering the whole spectrum of ARDs in contrast to other studies [14, 16]. Having that in mind, the high percentage of females $(75 \%)$ in our cohort can be explained. In fact, the majority of patients with 
Table 3 Comparison of patients who were never vaccinated vs. those who vaccinated at both time periods

\begin{tabular}{|c|c|c|c|}
\hline & $\begin{array}{l}\text { Never vaccinated } \\
(\mathrm{n}=145)\end{array}$ & $\begin{array}{l}\text { Vaccinated at both time } \\
\text { periods }(n=774)\end{array}$ & $p$ \\
\hline Age (years), median (range) & $49(21-80)$ & $60(18-82)$ & 0.0001 \\
\hline Female gender, $n(\%)$ & $109(75.2 \%)$ & $551(71.1 \%)$ & 0.836 \\
\hline Disease duration(years), median (range) & $7(0.5-48)$ & $7(0.5-50)$ & 0.516 \\
\hline $\begin{array}{l}\text { Type of ARD } \\
\text { Inflammatory arthritis } \\
\text { Connective tissue diseases } \\
\text { Auto-inflammatory diseases } \\
\text { Vasculitis }\end{array}$ & $\begin{array}{l}81 \\
53 \\
3 \\
8\end{array}$ & $\begin{array}{l}451 \\
216 \\
15 \\
62\end{array}$ & 0.267 \\
\hline Higher Educational status, $n(\%)$ & $57(39.3 \%)$ & $240(31.0 \%)$ & 0.103 \\
\hline Unemployed, $n(\%)$ & $25(17.2 \%)$ & $127(16.4 \%)$ & 1.000 \\
\hline Current smokers, $n(\%)$ & $46(31.7 \%)$ & $185(23.9 \%)$ & 0.09 \\
\hline \multicolumn{4}{|l|}{ Therapy } \\
\hline Glucocorticoids, $n(\%)$ & $44(30.3 \%)$ & $278(35.6 \%)$ & 0.110 \\
\hline Non-biologics, $n(\%)$ & $94(64.8 \%)$ & $496(64.1 \%)$ & 0.701 \\
\hline Biologics, $n(\%)$ & $64(44.1 \%)$ & $440(56.9 \%)$ & 0.001 \\
\hline \multicolumn{4}{|l|}{ Co-morbidities } \\
\hline Hypertension, $n(\%)$ & $35(24.1 \%)$ & $335(38.8 \%)$ & 0.0001 \\
\hline Coronary artery disease, $n(\%)$ & $6(4.1 \%)$ & $54(7.0 \%)$ & 0.207 \\
\hline Heart failure, $n(\%)$ & $3(2.1 \%)$ & $15(1.9 \%)$ & 1.000 \\
\hline Diabetes mellitus, $n(\%)$ & $7(4.8 \%)$ & $84(10.9 \%)$ & 0.016 \\
\hline Chronic Kidney Disease, $n(\%)$ & $7(4.8 \%)$ & $58(7.5 \%)$ & 0.294 \\
\hline Chronic Obstructive Pulmonary Disease, $n(\%)$ & $2(1.4 \%)$ & $39(5.0 \%)$ & 0.05 \\
\hline Neoplasia history, $n(\%)$ & $12(8.3 \%)$ & $57(7.4 \%)$ & 0.737 \\
\hline Chemotherapy, $n$ (\%) & $0(0 \%)$ & $3(0.3 \%)$ & 1.000 \\
\hline
\end{tabular}

Significant values $(p<0.05)$ are marked with bold inflammatory arthritis and connective tissue diseases in our cohort, suffered from rheumatoid arthritis and systemic lupus erythematosus or scleroderma, respectively. In these diseases, female population predominates. Second, it is not registry-based but data were obtained from telephoneinterviews. Said that it should be stressed that our questionnaire, was not externally validated, but it was specifically designed for this purpose by the investigators of this study. We acknowledge that our patients were followed in tertiary academic rheumatology clinics and therefore their adherence to national and international guidelines (including those for vaccinations) might be higher compared to the rest of the patient population. Finally, data for 2019/20 were retrospectively collected while there was no physician documented diagnosis of a disease flare.

In conclusion, we show that the flu vaccination rate increased significantly during the COVID-19 pandemic in a large, real-life cohort of patients with ARDs. This could have been in part due to the higher recommendation rate by their caring rheumatologists. These findings, although are temporally encouraging, emphasize the need for continuous campaigns aiming at increasing patients' and physicians' awareness about the benefits of vaccination.
Authors' contributions GEF: study design, data analysis and interpretation, drafting the manuscript. GG: study design, data analysis and interpretation, revising the manuscript. JM: data acquisition, revising the manuscript. AA: data acquisition, data analysis and interpretation, revising the manuscript. V-KB: data acquisition, data analysis and interpretation, revising the manuscript. GE: study design, data acquisition, data analysis and interpretation, drafting the manuscript. KF: data acquisition, data analysis and interpretation, revising the manuscript. AK: data acquisition, data analysis and interpretation, revising the manuscript. EK: data acquisition, data analysis and interpretation, revising the manuscript. SP: data acquisition, data analysis and interpretation, revising the manuscript. MP: data acquisition, data analysis and interpretation, revising the manuscript. KT: study design, data acquisition, data analysis and interpretation, revising the manuscript. MGT: study design, data acquisition, data analysis and interpretation, revising the manuscript. DP: study inception, study design, data acquisition, data analysis and interpretation, revising the manuscript. DV: study inception, study design, data acquisition, data analysis and interpretation, revising the manuscript. PPS: study inception, study design, data acquisition, data analysis and interpretation, revising the manuscript.

Funding This study has not received any funding.

Data availability All data are presented in the manuscript. Further details are available at reasonable request. 
Table 4 Comparison of patients who were newly vaccinated vs. those who did not change their vaccination behavior
Newly vaccinated patients

(in 2020-21 but not in 2019-20 period)

\begin{tabular}{|c|c|c|c|}
\hline & Yes $(n=99)$ & No $(n=889)$ & $p$ \\
\hline Age (years), median (range) & $52(19-80)$ & $58(18-82)$ & 0.0001 \\
\hline Female gender, $n(\%)$ & $78(78.8 \%)$ & $660(74.2 \%)$ & 0.394 \\
\hline Disease duration(years), median (range) & $4(0.5-40)$ & $7(0.5-50)$ & 0.007 \\
\hline $\begin{array}{l}\text { Type of ARD } \\
\text { Inflammatory arthritis } \\
\text { Connective tissue diseases } \\
\text { Auto-inflammatory diseases } \\
\text { Vasculitis }\end{array}$ & $\begin{array}{l}59 \\
26 \\
1 \\
13\end{array}$ & $\begin{array}{l}532 \\
229 \\
18 \\
70\end{array}$ & 0.274 \\
\hline Higher Educational status, $n(\%)$ & $51(51.5 \%)$ & $297(33.4 \%)$ & 0.001 \\
\hline Unemployed, $n(\%)$ & $20(20.2 \%)$ & $152(17.1 \%)$ & 0.405 \\
\hline Current smokers, $n(\%)$ & $25(25.2 \%)$ & $231(26.0 \%)$ & 1.000 \\
\hline \multicolumn{4}{|l|}{ Therapy } \\
\hline Glucocorticoids, $n(\%)$ & $39(39.4 \%)$ & $322(36.3 \%)$ & 0.582 \\
\hline Non-biologics, n (\%) & $59(59.6 \%)$ & $590(66.3 \%)$ & 0.182 \\
\hline Biologics, $n(\%)$ & $51(51.5 \%)$ & $504(56.7 \%)$ & 0.338 \\
\hline \multicolumn{4}{|l|}{ Co-morbidities } \\
\hline Hypertension, $n(\%)$ & $18(18.2 \%)$ & $335(37.7 \%)$ & 0.0001 \\
\hline Coronary artery disease, $n(\%)$ & $3(3.1 \%)$ & $61(6.7 \%)$ & 0.193 \\
\hline Heart failure, $n(\%)$ & $0(0 \%)$ & $18(2 \%)$ & 0.244 \\
\hline Diabetes mellitus, $n(\%)$ & $7(7 \%)$ & $91(10.2 \%)$ & 0.379 \\
\hline Chronic Kidney Disease, $n(\%)$ & $2(2 \%)$ & $65(7.3 \%)$ & 0.06 \\
\hline Chronic Obstructive Pulmonary Disease, $n(\%)$ & $2(2 \%)$ & $42(4.6 \%)$ & 0.305 \\
\hline Neoplasia history, $n(\%)$ & $3(3.1 \%)$ & $71(7.8 \%)$ & 0.102 \\
\hline Chemotherapy, $n(\%)$ & $0(0 \%)$ & $3(0.3 \%)$ & 1.000 \\
\hline
\end{tabular}

Significant values $(p<0.05)$ are marked with bold

$S D$ standard deviation

\section{Declarations}

Conflicts of interest The authors declare that they have no conflicts of interest.

Ethical approval This study was conducted according to the Declaration of Helsinki and was approved by the Scientific Council of the "Laiko" hospital (No: 2020/14/4).

Informed consent All patients have provided informed consent to participate into the study.

\section{References}

1. Thomas K, Vassilopoulos D (2016) Immunization in patients with inflammatory rheumatic diseases. Best Pract Res Clin Rheumatol 30:946-963. https://doi.org/10.1016/j.berh.2016.10.009

2. Fragoulis GE, Sipsas NV (2019) When rheumatology and infectious disease come together. Ther Adv Musculoskelet Dis. https ://doi.org/10.1177/1759720X19868901

3. Furer V, Rondaan C, Heijstek MW, Agmon-Levin N, van Assen S, Bijl M, Breedveld FC, D’Amelio R, Dougados M, Kapetanovic MC, van Laar JM, de Thurah A, Landewe RB, Molto A, MullerLadner U, Schreiber K, Smolar L, Walker J, Warnatz K, Wulffraat
NM, Elkayam O (2020) 2019 update of EULAR recommendations for vaccination in adult patients with autoimmune inflammatory rheumatic diseases. Ann Rheum Dis 79:39-52. https://doi. org/10.1136/annrheumdis-2019-215882

4. Nakafero G, Grainge MJ, Myles PR, Mallen CD, Zhang W, Doherty M, Nguyen-Van-Tam JS, Abhishek A (2020) Effectiveness of inactivated influenza vaccine in autoimmune rheumatic diseases treated with disease-modifying anti-rheumatic drugs. Rheumatology (Oxford) 59:3666-3675. https://doi.org/10.1093/ rheumatology/keaa078

5. Fragoulis GE, Evangelatos G, Arida A, Bournia VK, Fragiadaki K, Karamanakos A, Kravvariti E, Laskari K, Panopoulos S, Pappa M, Tektonidou MG, Sfikakis PP (2020) Treatment adherence of patients with systemic rheumatic diseases in COVID-19 pandemic. Ann Rheum Dis. https://doi.org/10.1136/annrheumdi s-2020-217935

6. Zhu N, Zhang D, Wang W, Li X, Yang B, Song J, Zhao X, Huang B, Shi W, Lu R, Niu P, Zhan F, Ma X, Wang D, Xu W, Wu G, Gao GF, Tan W, China Novel Coronavirus I, Research T (2020) A novel coronavirus from patients with pneumonia in China, 2019. N Engl J Med 382:727-733. https://doi.org/10.1056/NEJMoa2001 017

7. Lu R, Zhao X, Li J, Niu P, Yang B, Wu H, Wang W, Song H, Huang B, Zhu N, Bi Y, Ma X, Zhan F, Wang L, Hu T, Zhou H, Hu Z, Zhou W, Zhao L, Chen J, Meng Y, Wang J, Lin Y, Yuan J, Xie Z, Ma J, Liu WJ, Wang D, Xu W, Holmes EC, Gao GF, Wu G, Chen W, Shi W, Tan W (2020) Genomic characterisation and 
epidemiology of 2019 novel coronavirus: implications for virus origins and receptor binding. Lancet 395:565-574. https://doi. org/10.1016/S0140-6736(20)30251-8

8. Zhou P, Yang XL, Wang XG, Hu B, Zhang L, Zhang W, Si HR, Zhu Y, Li B, Huang CL, Chen HD, Chen J, Luo Y, Guo H, Jiang RD, Liu MQ, Chen Y, Shen XR, Wang X, Zheng XS, Zhao K, Chen QJ, Deng F, Liu LL, Yan B, Zhan FX, Wang YY, Xiao GF, Shi ZL (2020) A pneumonia outbreak associated with a new coronavirus of probable bat origin. Nature 579:270-273. https:// doi.org/10.1038/s41586-020-2012-7

9. Abate SM, Ahmed Ali S, Mantfardo B, Basu B (2020) Rate of Intensive Care Unit admission and outcomes among patients with coronavirus: a systematic review and Meta-analysis. PLoS ONE 15:e0235653. https://doi.org/10.1371/journal.pone.0235653

10. Guan WJ, Ni ZY, Hu Y, Liang WH, Ou CQ, He JX, Liu L, Shan H, Lei CL, Hui DSC, Du B, Li LJ, Zeng G, Yuen KY, Chen RC, Tang CL, Wang T, Chen PY, Xiang J, Li SY, Wang JL, Liang ZJ, Peng YX, Wei L, Liu Y, Hu YH, Peng P, Wang JM, Liu JY, Chen Z, Li G, Zheng ZJ, Qiu SQ, Luo J, Ye CJ, Zhu SY, Zhong NS, China Medical Treatment Expert Group for C (2020) Clinical characteristics of coronavirus disease 2019 in China. N Engl J Med 382:1708-1720. https://doi.org/10.1056/NEJMoa2002032

11. Lechien JR, Chiesa-Estomba CM, Place S, Van Laethem Y, Cabaraux P, Mat Q, Huet K, Plzak J, Horoi M, Hans S, Rosaria Barillari M, Cammaroto G, Fakhry N, Martiny D, Ayad T, Jouffe L, Hopkins C, Saussez S, YO-IFOS C-TFo, (2020) Clinical and epidemiological characteristics of 1420 European patients with mildto-moderate coronavirus disease 2019. J Intern Med 288:335-344. https://doi.org/10.1111/joim.13089

12. Popov GT, Baymakova M, Vaseva V, Kundurzhiev T, Mutafchiyski V (2020) Clinical Characteristics of Hospitalized Patients with COVID-19 in Sofia, Bulgaria. Vector Borne Zoonotic Dis 20:910-915. https://doi.org/10.1089/vbz.2020.2679

13. Domnich A, Cambiaggi M, Vasco A, Maraniello L, Ansaldi F, Baldo V, Bonanni P, Calabro GE, Costantino C, de Waure C, Gabutti G, Restivo V, Rizzo C, Vitale F, Grassi R (2020) Attitudes and Beliefs on Influenza Vaccination during the COVID-19 Pandemic: Results from a Representative Italian Survey. Vaccines (Basel). https://doi.org/10.3390/vaccines8040711

14. Costello R, Winthrop KL, Pye SR, Brown B, Dixon WG (2016) Influenza and pneumococcal vaccination uptake in patients with rheumatoid arthritis treated with immunosuppressive therapy in the UK: a retrospective cohort study using data from the clinical practice research datalink. PLoS ONE 11:e0153848. https://doi. org/10.1371/journal.pone.0153848

15. Nakafero G, Grainge MJ, Myles PR, Mallen CD, Zhang W, Doherty M, Nguyen-Van-Tam JS, Abhishek A (2018) Predictors and temporal trend of flu vaccination in auto-immune rheumatic diseases in the UK: a nationwide prospective cohort study. Rheumatology (Oxford) 57:1726-1734. https://doi.org/10.1093/rheum atology/key 156

16. Nguyen M, Lindegaard H, Hendricks O, Friis-Moller N (2017) Factors associated with influenza and pneumococcal vaccine uptake among rheumatoid arthritis patients in Denmark invited to participate in a pneumococcal vaccine trial (Immunovax_RA). Scand J Rheumatol 46:446-453. https://doi.org/10.1080/03009 742.2016.1242774

17. Papadopoulou D, Trontzas P (2017) A survey to evaluate the implementation of vaccine recommendations among rheumatologists practicing in Greece. Mediterr J Rheumatol 28:41-47. https ://doi.org/10.31138/mjr.28.1.41
18. Gosselin Boucher V, Colmegna I, Gemme C, Labbe S, Pelaez S, Lavoie KL (2019) Interventions to improve vaccine acceptance among rheumatoid arthritis patients: a systematic review. Clin Rheumatol 38:1537-1544. https://doi.org/10.1007/s10067-01904430-7

19. Thomas K, Lazarini A, Kaltsonoudis E, Drosos A, Repa A, Sidiropoulos P, Fragkiadaki K, Tektonidou M, Sfikakis P, Tsatsani P, Gazi S, Katsimbri P, Boumpas D, Argyriou E, Boki K, Evangelatos G, Iliopoulos A, Karagianni K, Sakkas L, Melissaropoulos K, Georgiou P, Grika E, Vlachoyiannopoulos P, Dimitroulas T, Garyfallos A, Georganas C, Vounotrypidis P, Ntelis K, Areti M, Kitas GD, Vassilopoulos D (2020) AB1201 increasing rates of influenza vaccination coverage in rheumatoid arthritis patients: data from a multicenter, longitudinal cohort study of 1,406 patients. Ann Rheum Dis 79:1892-1892. https://doi.org/10.1136/annrheumdi s-2020-eular.4812

20. Papaioannou A, Konstantinidi AE, Primikiri E, Asimakopoulou F, Aravantinos D, Mavromichali Z (2020) Influenza vaccination rate among high risk group patients in primary health care in Greece. Cent Eur J Public Health 28:297-301. https://doi.org/10.21101/ cejph.a5237

21. Machado A, Kislaya I, Santos AJ, Gaio V, Gil AP, Barreto M, Namorado S, Antunes L, Matias Dias C, Nunes B (2018) Factors associated to repeated influenza vaccination in the Portuguese adults with chronic conditions. Vaccine 36:5265-5272. https:// doi.org/10.1016/j.vaccine.2018.07.041

22. Holvast A, Stegeman CA, Benne CA, Huckriede A, Wilschut JC, Palache AM, Kallenberg CG, Bijl M (2009) Wegener's granulomatosis patients show an adequate antibody response to influenza vaccination. Ann Rheum Dis 68:873-878. https://doi.org/10.1136/ ard.2008.092924

23. Saad CG, Borba EF, Aikawa NE, Silva CA, Pereira RM, Calich AL, Moraes JC, Ribeiro AC, Viana VS, Pasoto SG, Carvalho JF, Franca IL, Guedes LK, Shinjo SK, Sampaio-Barros PD, Caleiro MT, Goncalves CR, Fuller R, Levy-Neto M, Timenetsky Mdo C, Precioso AR, Bonfa E (2011) Immunogenicity and safety of the 2009 non-adjuvanted influenza A/H1N1 vaccine in a large cohort of autoimmune rheumatic diseases. Ann Rheum Dis 70:10681073. https://doi.org/10.1136/ard.2011.150250

24. Setti M, Fenoglio D, Ansaldi F, Filaci G, Bacilieri S, Sticchi L, Ferrera A, Indiveri F, Ghio M (2009) Flu vaccination with a virosomal vaccine does not affect clinical course and immunological parameters in scleroderma patients. Vaccine 27:3367-3372. https ://doi.org/10.1016/j.vaccine.2009.01.078

25. Perdan-Pirkmajer K, Thallinger GG, Snoj N, Cucnik S, Zigon P, Kveder T, Logar D, Praprotnik S, Tomsic M, Sodin-Semrl S, Ambrozic A (2012) Autoimmune response following influenza vaccination in patients with autoimmune inflammatory rheumatic disease. Lupus 21:175-183. https://doi.org/10.1177/0961203311 429817

26. Murray K, Low C, O'Rourke A, Young F, Callanan I, Feeney E, Veale DJ (2020) A quality improvement intervention failed to significantly increase pneumococcal and influenza vaccination rates in immunosuppressed inflammatory arthritis patients. Clin Rheumatol 39:747-754. https://doi.org/10.1007/s10067-019-04841-6

Publisher's Note Springer Nature remains neutral with regard to jurisdictional claims in published maps and institutional affiliations. 


\section{Authors and Affiliations}

\section{George E. Fragoulis ${ }^{1}\left[\right.$ () Ioannis Grigoropoulos ${ }^{2} \cdot$ Evgenia Mavrea $^{2} \cdot$ Aikaterini Arida $^{1}$ (i) .

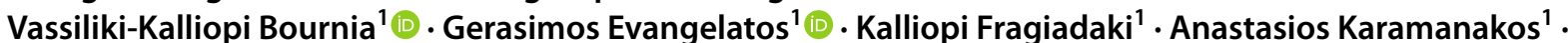

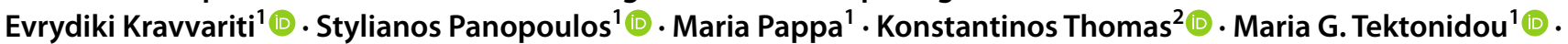 Dimitrios Paraskevis ${ }^{3}\left[\right.$. Dimitrios Vassilopoulos ${ }^{2}$ (1) Petros P. Sfikakis ${ }^{1}[$}

Ioannis Grigoropoulos

grigoropoulosioannis@gmail.com

Evgenia Mavrea

jenny.mavrea96@gmail.com

Aikaterini Arida

aridakater@yahoo.gr

Vassiliki-Kalliopi Bournia

lily_bournia@hotmail.com

Gerasimos Evangelatos gerevag@gmail.com

Kalliopi Fragiadaki po_fragiadaki@yahoo.gr

Anastasios Karamanakos tkar_84@hotamail.com

Evrydiki Kravvariti euridicek@gmail.com

Stylianos Panopoulos sty.panopoulos@gmail.com

Maria Pappa

mariak.pappa@yahoo.com
Konstantinos Thomas

costas_thomas@yahoo.com

Maria G. Tektonidou

mtektonidou@gmail.com

Dimitrios Paraskevis

dparask@med.uoa.gr

Dimitrios Vassilopoulos

dvassilop@med.uoa.gr

Petros P. Sfikakis

psfikakis@med.uoa.g

1 Rheumatology Unit, First Department of Propaedeutic Internal Medicine, Joint Rheumatology Program,

National and Kapodistrian University of Athens Medical School, Laiko General Hospital, MikrasAsias 75 Street, 11527 Athens, Greece

2 2nd Department of Medicine and Laboratory, Clinical Immunology-Rheumatology Unit, Hippokration General Hospital, Athens, Greece

Department of Hygiene Epidemiology and Medical Statistics, Medical School, National and Kapodistrian University of Athens, Athens, Greece 